\title{
PHASE CHANGE MATERIAL DARI CAMPURAN PARAFIN UNTUK TEKSTIL SWA-TERMORE GULASI
}

\author{
PHASE CHANGE MATERIAL FROM BINARY MIX PARAFFINS FOR \\ SELF-THERMOREGULATING TEXTILES
}

Tisna Kusumah ${ }^{1 *}$, Tatang Wahyudi ${ }^{2}$, dan Mohamad Widodo ${ }^{1}$

1. Politeknik STTT, Bandung, 40272, Indonesia

2. Balai Besar Tekstil, Bandung, 40272, Indonesia

*E-mail: tisnakusumah@gmail.com

\begin{abstract}
ABSTRAK
Phase change material (PCM) organik seperti lilin parafin memiliki kemampuan untuk menyerap sejumlah energi panas atau entalpi $(\mathrm{kJ} / \mathrm{kg})$ pada saat lilin parafin mengalami perubahan fase dari padat ke cair, dan sebaliknya, melepaskan energi panas saat berubah fase dari cair ke padat. Kemampuan unik lilin parafin ini telah diteliti oleh banyak peneliti seperti mengenai sifat-sifat termal dan pemanfaatannya sebagai thermal energy storage. Penelitian-penelitian tentang PCM organik yang telah dikerjakan, umumnya menggunakan bahan kelas sintesa yang memiliki keunggulan dalam hal kemurnian tetapi memiliki kesulitan untuk diaplikasikan dalam skala industri karena faktor keekonomisan dan ketersediaan bahan yang sulit didapat dalam skala besar. Oleh karena itu, penelitian ini difokuskan untuk mengetahui perubahan sifat termal dari campuran lilin parafin padat dan cair kelas mutu industri sebagai bahan utama PCM yang dapat dimanfaatkan dalam industri tekstil untuk membuat material tekstil yang responsif dan adaptif terhadap perubahan suhu lingkungan. Hasil analisa DSC menunjukkan bahwa pencampuran lilin parafin padat:cair dengan komposisi 9:1, 8:2, 7:3, dan 6:4 memperlihatkan adanya pembentukan entitas senyawa baru dengan sifat termal yang berbeda. Masing-masing kombinasi campuran yang berbeda memiliki titik leleh dan kandungan entalpi yang semakin menurun dari 60,4 ${ }^{\circ} \mathrm{C}(9: 1)$ ke 51,4 (6:4).
\end{abstract}

Kata kunci: PCM, lilin parafin, sifat termal.

\begin{abstract}
Paraffin wax as PCM has capability of absorbing an amount of heat $(\mathrm{kJ} / \mathrm{kg})$ when its phase changes from solid to liquid.and vise versa. This unique ability of the PCM has been explored and investigated by many researchers including their thermal properties and applications as thermal energy storage. The previous researches generally used analytical grade of materials with high purity. However, it is difficult to use it in an industrial scale of production because the cost and the availability. Therefore, this research was focused on studying the changes in the thermal properties of mixture of industrial grade paraffin waxes as PCM with different melting points in the form of solid and liquid respectively. The resulting PCM can be used for textile finishing industry to make a textile material which is responsive and adaptive to the environment temperatures. Analysis with DSC showed that the mixing with ratios of solid:liquid 9:1, $8: 2,7: 3$, and 6:4 respectively exhibited an indication of new entity formation with different thermal properties. The higher proportion of the liquid resulted in the lower
\end{abstract}


melting temperature of the resulting mixtures (decreasing from $60,4{ }^{\circ} \mathrm{C}$ of the $9: 1$ mixture to $51,4{ }^{\circ} \mathrm{C}$ of the $6: 4$ mixture).

Keywords: PCM, paraffin wax, thermal properties.

\section{PENDAHULUAN}

PCM (phase change materials) adalah material yang memiliki kemampuan untuk melepas/menyerap sejumlah energi pada transisi fase yang dimanfaatkan untuk menyimpan energi (Sarier \& Onder, 2012). Berdasarkan jenis perubahan fasenya PCM digolongkan ke dalam 4 golongan yaitu fase padat - padat, padat - cair, cair gas, dan cair - cair (Sharma, 2005). Sebagai thermal energy storage (TES) yang bersifat pasif (Hale et al., 1971), PCM memiliki fungsi untuk mengontrol suhu. Keunikan PCM terletak pada kemampuannya berubah fase disertai dengan penyerapan dan pelepasan sejumlah tertentu kalor. Kemampuan PCM dalam hal menyerap dan melepaskan panas ini dimanfaatkan dalam bidang tekstil sebagai material penyempurnaan untuk mendapatkan sifat bahan yang memiliki kemampuan responsif dan adaptif terhadap perubahan suhu luar, dan menjaga suhu lingkungan mikro (microclimate) pada suatu rentang tertentu yang diinginkan. Tujuan utamanya adalah melindungi pemakai dari paparan perubahan suhu lingkungan sehingga kenyamanan termal dapat tetap dipertahankan, baik dalam kondisi cuaca panas maupun dingin. Pemanfaatan PCM sebagai penyimpan panas yang dapat diaplikasikan pada material tekstil untuk menghasilkan suatu produk yang memiliki sifat responsif dan adaptif terhadap berbagai kondisi cuaca memiliki prospek masa depan yang sangat baik mengingat pemanfaatannya masih sangat terbatas. Tidak seperti bidang konstruksi ataupun transportasi barang dan Iain-lain, aplikasi PCM pada bahan tekstil belum terlalu banyak berkembang karena persyaratan proses maupun produk akhirnya harus menyesuaikan dengan tujuan penggunaan dan keunikan material tekstil yang bersifat fleksibel dan berpori. PCM organik dan campurannya yang dapat berubah fase pada rentang suhu $18-65^{\circ} \mathrm{C}$ cocok untuk dipakai pada aplikasi tekstil dan bangunan (Sarier \& Onder, 2012). Rentang suhu tersebut cukup lebar sehingga memungkinkan 
pengembangan

produk

penyempurnaan untuk kenyamanan termal tekstil dengan ragam aplikasi yang luas seperti otomotif, furnitur dan perlengkapan rumah tangga, perlengkapan aktifitas outdoor, dan garmen yang bersentuhan langsung dengan kulit. Dalam aplikasi tekstil, produk penyempurnaan kenyamanan termal berbasis PCM harus memiliki rentang perubahan fase yang mendekati suhu tubuh manusia, yaitu 35ㄷ (Mondal, 2008b). Untuk mencapainya, dapat digunakan bahan PCM berbasis n-alkana seperti eikosan $\left(\mathrm{C}_{20} \mathrm{H}_{42}\right)$ (Alkan, Sari, \& Karaipekli, 2011) atau PEG (polietilena glikol) 1000 (Hopp, Smausz, Tombácz, Wittmann, \& Ignácz, 2000). Kelebihan PCM dengan bahan-bahan tersebut adalah kemurniannya yang tinggi sehingga proses karakterisasi dan hasil produk yang dihasilkan baik dan stabil dalam siklus membeku, meleleh, dan entalpinya.

Prinsip mekanisme penyimpanan kalor pada PCM adalah melalui penyimpanan dan pelepasan kalor laten. Saat sumber panas naik, ikatan kimia di antara molekul PCM lepas. Dalam konteks PCM padat - cair, material tersebut menjadi meleleh atau mencair. Reaksi perubahan fase tersebut bersifat endotermik. Sebaliknya, bila temperatur sumber panas turun, maka PCM akan membeku dengan diiringi reaksi eksotermik yang berarti terjadi proses pelepasan panas sampai proses pembekuan selesai (Sharma, 2005). Melalui pelelehan atau pemadatan pada suhu perubahan fasenya (PCT phase change temperature), suatu PCM mampu menyimpan dan melepaskan sejumlah besar energi. Perubahan fase tersebut merujuk pada kemampuan material menyimpan kalor laten (LHS - latent heat storage), atau dalam istilah lainnya disebut entalpi. Secara umum, PCM dikelompokkan ke dalam dua jenis: (1) bahan organik (mengandung karbon) yang berasal dari sumber minyak bumi, tumbuhan, atau hewan; dan (2) bahan garam hidrat yang umumnya menggunakan garam-garam alami dari laut, dari endapan mineral, atau hasil reaksi samping dari proses yang lain (S. Himran, 1994).

Dalam proses perubahan fase PCM, penyimpanan kalor laten merupakan cara paling efisien untuk menyimpan energi panas. Tidak seperti metode penyimpanan sensible heat (panas yang menyebabkan perubahan suhu suatu objek), kalor laten mampu 
menyimpan panas pada densitas lebih tinggi dengan rentang perubahan suhu disimpan dan dilepas yang lebih kecil. Setiap material menyerap panas dari lingkungan dalam peristiwa pemanasan yang menyebabkan naiknya suhu material secara konstan, serta melepas panas ke lingkungan dalam proses pendinginan, sehingga suhu material pun menurun secara kontinyu. Bila dibandingkan, penyerapan panas saat material meleleh lebih tinggi dibandingkan dengan penyerapan panas oleh material dalam keadaan normalnya. Sebagai contoh, PCM dari lilin parafin menyerap sekitar $200 \mathrm{~kJ} / \mathrm{kg}$ panas saat dalam proses pelelehan. Panas dalam jumlah besar yang diserap oleh lilin parafin tersebut akan dilepaskan ke lingkungan dalam proses pendinginan bahan, yang dimulai sejak tercapainya suhu kristalisasi material PCM tersebut. Secara skematis, proses perubahan fase dari padat ke cair ditunjukkan pada Gambar 1.
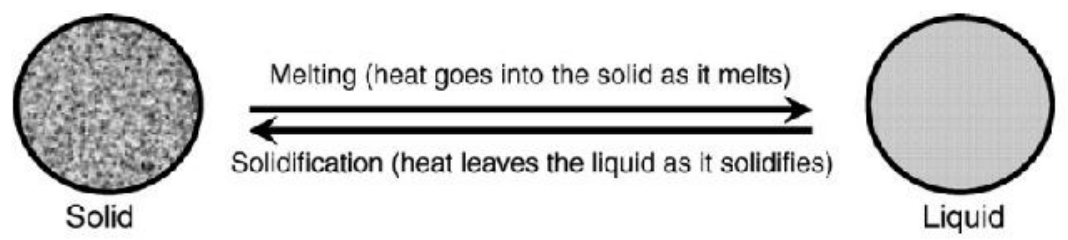

\section{Gambar 1. Gambaran skematik proses perubahan fase (Mondal, 2008a).}

Perubahan fase suatu PCM dapat terjadi dari padat ke cair, atau padat ke gas, cair ke gas, atau bahkan padat ke padat. Namun demikian, untuk aplikasi pada bahan tekstil, jenis PCM yang paling banyak digunakan adalah yang berubah fase dari padat ke cair atau sebaliknya. Saat suatu PCM mencapai suhu lelehnya dalam proses pemanasan, maka pada saat tersebut terjadi perubahan fase dari padat ke cair. Perubahan keadaan tersebut dapat diamati melalui analisa termal menggunakan DSC (differential scanning calorimetry). Kurva pada Gambar 2 memperlihatkan skema termogram dari proses pelelehan PCM. 


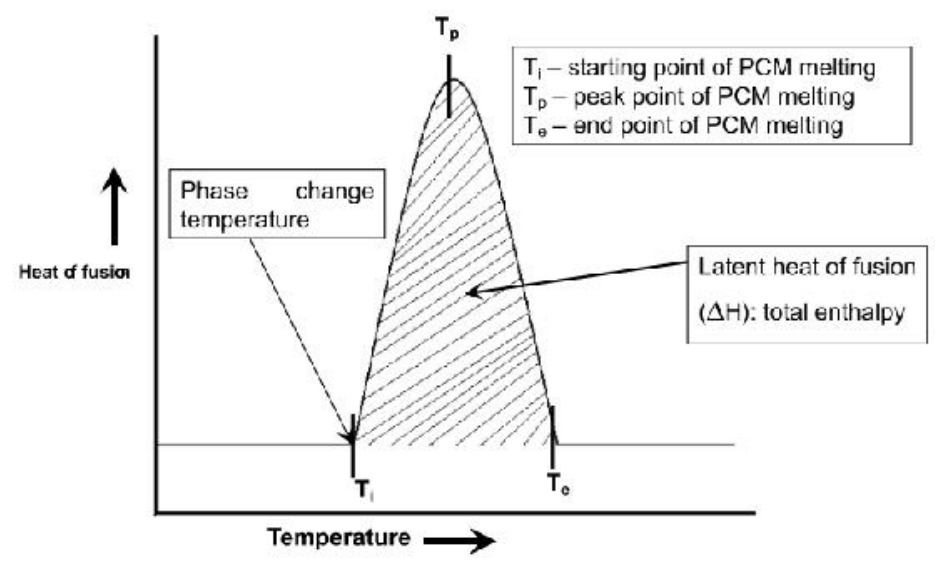

\section{Gambar 2. Skema tipe termogram DSC pada pemanasan PCM (Mondal, 2008a)}

Bahan lain yang dapat dijadikan sebagai PCM adalah lilin parafin yang merupakan campuran normal-, iso-, siklo-alkana dan alkil benzena (Luyt \& Krupa, 2008). Hidrokarbon parafin merupakan istilah yang lazim digunakan untuk merujuk pada produk minyak mineral (petroleum) yang mengandung atom karbon organik dalam kelompok alkana $\left(\mathrm{C}_{\mathrm{n}} \mathrm{H}_{2 \mathrm{n}+2}\right)$ (Mondal, 2008a). Keberadaan parafin dalam minyak bumi mentah dapat menyebabkan masalah pengerakan karena terbentuknya lilin di dalam instalasi proses produksi minyak bumi seperti pada sumur dan juga pipa-pipa saluran pengeboran. Namun demikian, lilin parafin dan mikrokristal merupakan produk kilang minyak yang cukup penting, mengingat tingkat permintaan yang terus meningkat (S. Himran, 1994), sehingga pada akhirnya hidrokarbon parafin berubah dari hasil reaksi samping menjadi salah satu produk utama yang memang dibuat dari proses proses kilang minyak. Parafin murni biasanya hanya mengandung gugus alkana. Empat kelompok alkana pertama (metana hingga butana) berada dalam fase gas pada suhu ruang dan tekanan atmosfir. Alkana dengan jumlah atom karbon antara 517 memiliki bentuk cair, sedangkan alkana dengan jumlah atom karbon di atas 17 memiliki bentuk padat bersifat seperti lilin pada suhu ruang. Titik leleh dan kalor peleburan (heat of fusion) suatu senyawa alkana meningkat seiring dengan meningkatnya jumlah atom karbon

Lilin parafin secara umum merupakan senyawa polidispersi yang terdiri atas campuran dengan komposisi terbesar berupa n-alkana, dengan jumlah 
melebihi 75\% (hingga mencapai 100\%), dengan sisa komponen berupa isoalkana, siklo-alkana, dan alkil benzena (Luyt \& Krupa, 2008). Massa molekul senyawa hidrokarbon dalam bentuk cincin parafin bervariasi dari sekitar 280-560 ( $\left(\mathrm{C}_{20}-\mathrm{C}_{40}\right)$ dengan masingmasing lilin spesifik memiliki jumlah atom karbon bervariasi antara 8 hingga 15 (Krupa \& Mikova, 2007). Kelebihannya adalah kemudahan untuk didapat di pasaran, khususnya perusahaan penyedia kimia industri tekstil di Bandung dan harga yang relatif murah terutama untuk lilin parafin dengan kelas mutu industri (industrial grade) dengan kisaran harga USD 1.8 2.3 per $\mathrm{kg}$. Hal inilah yang mendasari dilakukannya penelitian ini, yaitu untuk mendapatkan produk PCM sebagai bahan utama penyempurnaan kenyamanan termal yang mudah diadaptasi dalam skala industri. Secara hipotesa, pencampuran PCM dengan titik leleh berbeda diduga dapat memberikan efek perubahan terhadap sifat termalnya karena adanya interaksi antara molekul-molekul yang dicampurkan.

Pada tahap berikutnya, secara umum aplikasi PCM ke dalam bahan tekstil yang sudah dikerjakan saat ini adalah dengan mewadahi PCM dalam suatu wadah tertutup agar jumlah PCM atau kandungan entalpinya selalu tersedia dalam jumlah tetap (tidak boleh berkurang atau hilang sama sekali). Potensi kehilangan kandungan entalpi dapat terjadi karena kehilangan PCM akibat kebocoran atau penguapan. Khusus pada aplikasi tekstil, teknik mewadahi PCM ini harus tetap dapat mempertahankan kaidah dan sifat utama material tekstil yaitu fleksibel dan berporos. Aplikasi PCM pada bahan tekstil yang sudah berhasil dikerjakan saat ini adalah dengan mengintegrasikan langsung pada serat, mewadahi dalam kapsul berukuran mikro atau nano dan diaplikasikan ke dalam bahan tekstil dengan metode pelapisan dengan bantuan suatu zat pengikat, membungkus PCM dalam suatu film tipis dengan ukuran tertentu yang kemudian ditempelkan pada bagian tertentu dari produk garmen. Namun demikian, hasil penelitian yang dilaporkan pada artikel ini merupakan studi awal, sehingga difokuskan pada teknik pencampuran lilin parafin yang berbeda titik lelehnya agar dapat diatur temperatur perubahan fasenya saat dimanfaatkan sebagai bahan PCM. Langkah berikutnya berupa pembuatan 
mikrokapsul dan aplikasinya pada bahan tekstil tidak dilaporkan.

Penelitian ini merupakan salah satu bagian dari rangkaian penelitian pembuatan dan karakterisasi mikrokapsul untuk mendapatkan

\section{METODA PENE LITIAN}

Penelitian ini dibagi ke dalam dua tahap, yaitu: (1) pencampuran lilin parafin dan (2) analisa sifat termalnya dengan menggunakan DSC (differential scanning calorimetry).

\subsection{Alat dan Bahan}

Alat yang digunakan untuk melakukan teknik pencampuran dua jenis lilin parafin yang memiliki titik leleh berbeda adalah piala gelas berukuran $50 \mathrm{ml}$, pemanas elektrik merk Witeg model SMHS $3 / 6$ dengan suhu max $360^{\circ} \mathrm{C}$ dan rpm max 1500, Timbangan analitik merk Precisa tipe XB 220A dengan ketelitian 0,0001g, termometer, pengaduk, dan pengatur waktu. Bahan yang digunakan adalah lilin parafin padat kelas mutu industri (Bratachem, Indonesia) dan lilin parafin cair kelas mutu industri (Bratachem, Indonesia). Untuk analisa termal, digunakan DSC kenyataman termal pada bahan tekstil yang bersifat adaptif dan responsif yang bertujuan untuk mempelajari perubahan sifat termal dari campuran dua jenis lilin parafin padat dan cair kelas mutu industri untuk digunakan sebagai bahan utama inti mikrokapsul.

merk NETZSCH tipe DSC 214 Polyma (Netzsch-Geratebau Gmbh, Jerman).

\subsection{Metode}

Teknik pencampuran parafin dilakukan di Laboratorium Lingkungan Balai Besar Tekstil, Bandung. Dua jenis parafin dengan titik leleh berbeda (padat dan cair) dicampurkan dengan variasi komposisi padat:cair masingmasing sebesar 9:1, 8:2, 7:3, dan 6:4. Dalam penelitian ini, jumlah total campuran parafin yang dibuat adalah $10 \mathrm{~g}$, sehingga angka perbandingan setara dengan berat bahan yang ditimbang (misalnya: komposisi 9:1 berarti mengandung $9 \mathrm{~g}$ parafin padat dan 1 gram parafin cair, dan seterusnya). Setelah ditimbang sesuai dengan komposisinya, masing-masing parafin padat dan cair dicampurkan di dalam piala gelas $50 \mathrm{ml}$. Campuran dipanaskan hingga mencapai suhu 70 ${ }^{\circ} \mathrm{C}$ selama 30 menit dengan pengadukan konsisten. Pada tahap ini, 
perlu dipastikan bahwa semua parafin yang dicampurkan mencapai kondisi meleleh. Setelah meleleh, campuran didinginkan dan kemudian dimasukkan ke dalam kotak sampel untuk diuji karakteristik termalnya. Analisa DSC dilakukan di LPTB (Loka Penelitian Teknologi Bersih), LIPI, Bandung untuk mengetahui titik leleh dan titik beku serta nilai entalpinya.

\section{HASIL DAN PEMBAHASAN}

Percobaan pencampuran lilin parafin padat dan cair bertujuan untuk mengetahui perilaku sifat termal parafin campuran dan mendapatkan kombinasi yang memiliki titik leleh dan beku yang mendekati suhu kenyamanan tubuh manusia. Secara visual, PCM parafin hasil pencampuran memiliki kenampakan berupa padatan dengan kekerasan material yang berbeda dengan wujud aslinya. Hasil pencampuran tidak didokumentasikan secara khusus, namun langsung dianalisa sifat termalnya dengan menggunakan DSC.

DSC digunakan untuk mengetahui titik leleh lilin parafin dan kandungan entalpi atau kalor laten dari campuran lilin parafin. Gambar 3 menyajikan kurva DSC dari campuran lilin parafin dengan komposisi masing-masing 9:1, 8:2, 7:3, dan 6:4 secara keseluruhan agar mudah untuk dibandingkan.

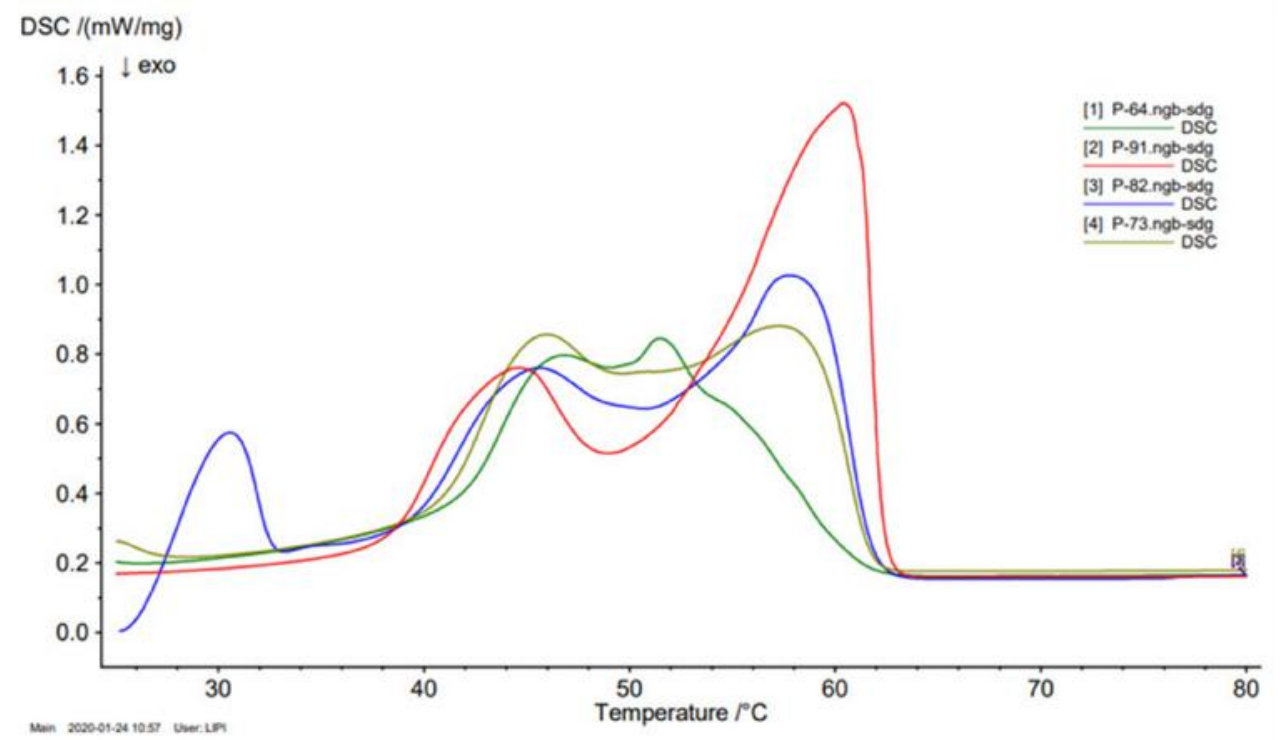

Gambar 3. Kurva DSC semua variasi kombinasi lilin parafin padat dan cair (9:1, 8:2, 7:3, dan 6:4) 
Gambar 3 menunjukkan bahwa bahwa setiap campuran dengan komposisi berbeda-beda menghasilkan suatu entitas baru dengan dua puncak titik leleh berbeda pula. Hal ini menunjukkan bahwa pencampuran tidak membentuk senyawa baru, namun menghasilkan campuran dua entitas dengan perubahan sifat termal dengan fenomena interaksi yang berbeda. Untuk lebih jelas, kurva DSC masing-masing campuran disajikan pada Gambar 4 (a)-(d).

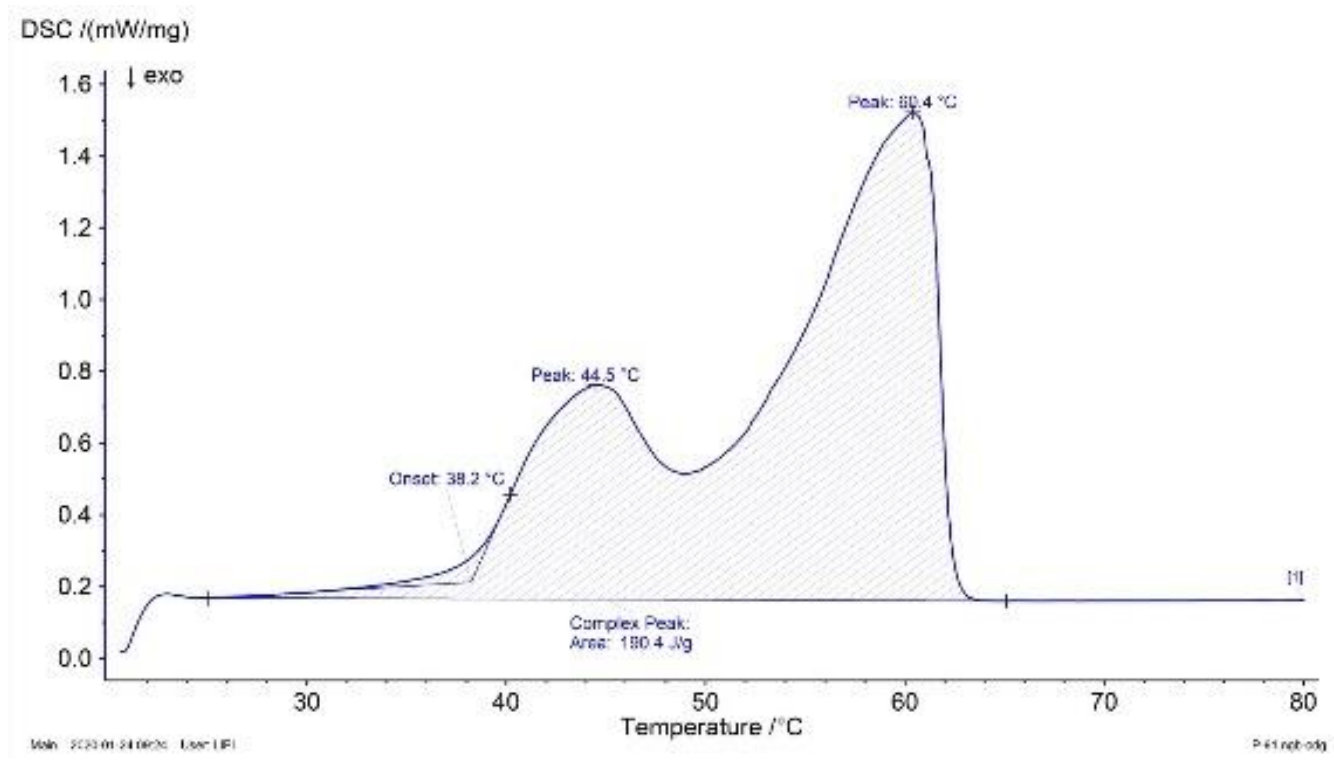

(a)

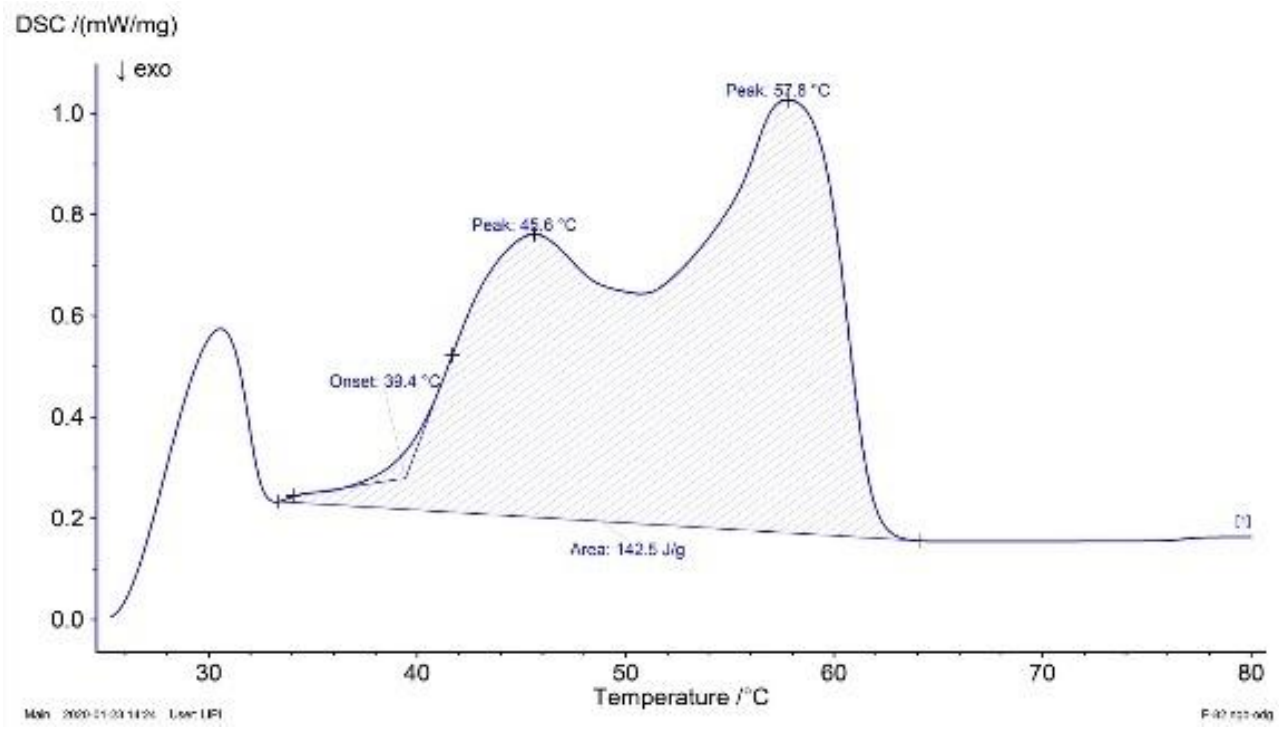

(b) 


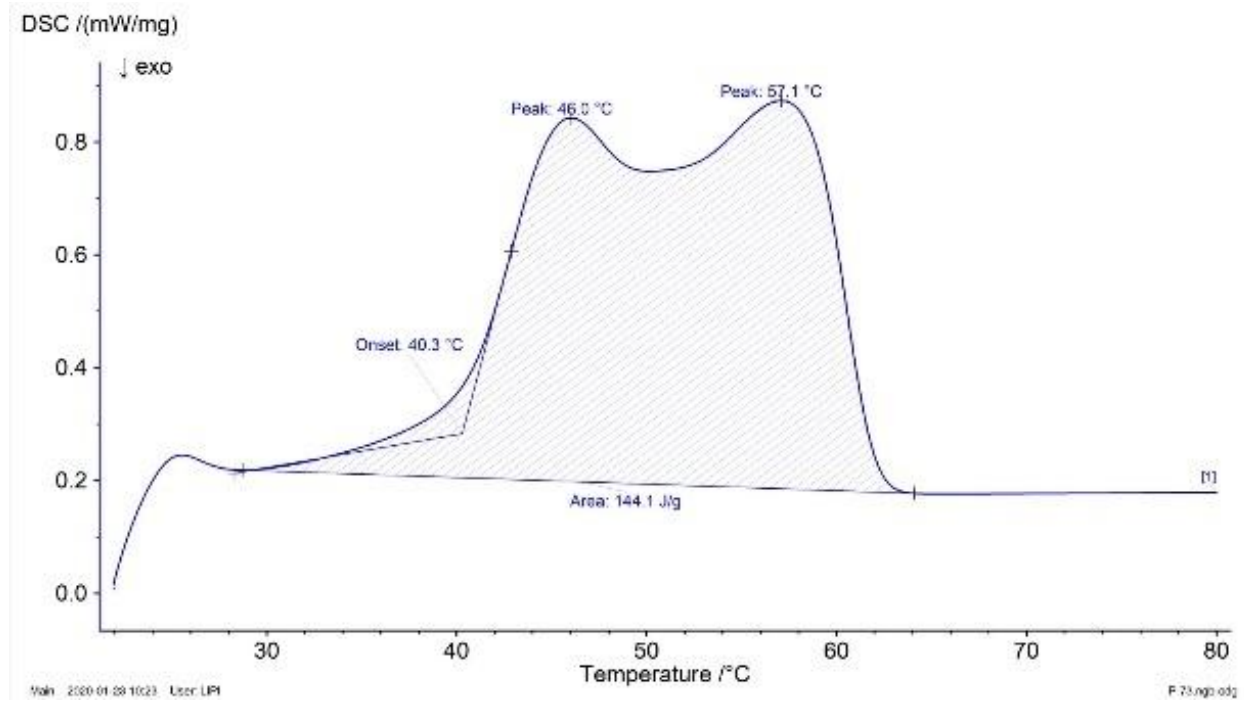

(c)

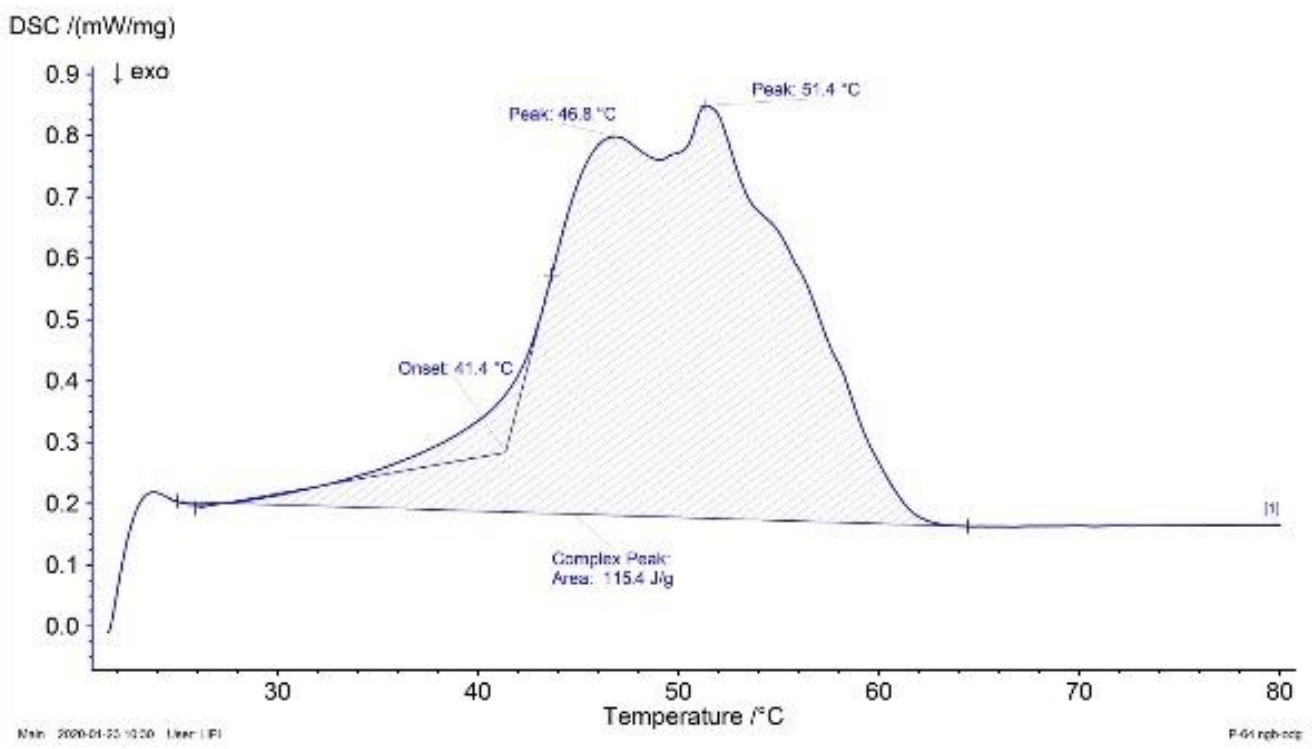

(d)

Gambar 4. Kurva DSC campuran lilin parafin padat dan cair dengan komposisi masingmasing: a) 9:1; b) 8:2; c) 7:3; dan d) 6:4. 
Pencampuran lilin parafin padat dan cair dilakukan sebagai upaya untuk menurunkan titik leleh dari $65 \stackrel{\circ}{\circ}$ menjadi suhu yang lebih mendekati suhu tubuh manusia. Dari kurva yang disajikan pada Gambar 4, dapat dilihat bahwa meningkatkan komposisi lilin parafin cair dalam campuran dapat secara bertahap menurunkan titik lelehnya. Pada perbandingan lilin parafin padat:cair 9:1 hingga 6:4, titik lelehnya cenderung terus menurun dari $60,4^{\circ} \mathrm{C}$ menjadi $51,4^{\circ} \mathrm{C}$. Hal tersebut menunjukkan bahwa pencampuran 2 jenis lilin parafin yang berbeda sifat fisikanya dapat saling mempengaruhi sifat termal dari keadaan tunggalnya dan didapatkan entitas baru dengan sifat termal yang baru.

Sifat termal, berat dan ukuran molekul lilin parafin ditentukan oleh banyaknya atom karbon yang menjadi penyusunnya. Semakin panjang rantai karbon maka semakin tinggi titik lelehnya dan semakin berat dan besar ukuran molekulnya. Semakin besar ukuran molekulnya, maka gaya interaksi dan antaraksi molekulnya juga semakin besar. Hal tersebut sesuai dengan teori mengenai gaya-gaya fisika antar molekul seperti gaya dispersi London dan gaya Van der Waals (Chang, 2010)
Besarnya gaya interaksi dan antaraksi molekular ini menjadi penentu sifat termal lilin parafin. Pada saat lilin parafin berubah fase dari padat menjadi cair (meleleh), yang terjadi adalah putusnya ikatan antar molekul senyawa alkana. Pemutusan ikatan ini memerlukan energi panas dan karenanya bersifat endotermik (menyerap panas). Sebaliknya saat lilin parafin berubah fase dari cair menjadi padat maka ikatan yang terputus tadi tersambung kembali dengan menghasilkan reaksi eksoterm atau melepaskan panas. Besarnya energi yang dibutuhkan atau dilepaskan saat pemutusan dan bersambung kembali dalam ikatan antar molekul tersebut dikenal juga dengan istilah kalor laten. Uraian tersebut menjelaskan mengapa PCM dapat menyerap dan melepaskan panas saat terjadi perubahan fase.

Pada saat dua jenis lilin parafin dengan jumlah rantai karbon yang berbeda dicampurkan dengan metode pemanasan dan dihasilkan suatu campuran baru yang homogen, maka kemungkinan yang terjadi adalah perubahan susunan molekulnya. Menurut literatur (Krupa \& Mikova, 2007), parafin cair pada umumnya memiliki jumlah rantai karbon yang lebih kecil (rantai molekul lebih pendek) 


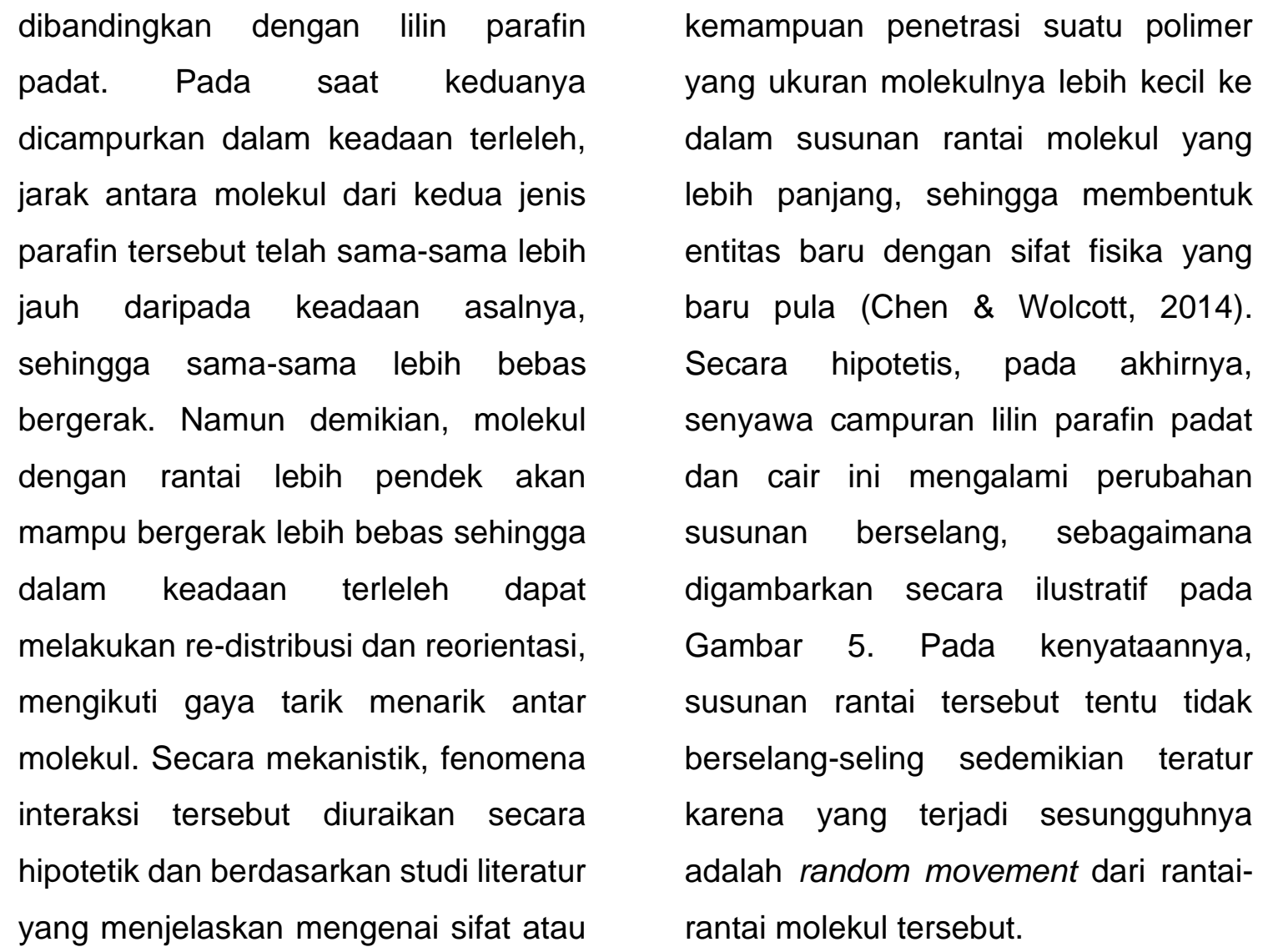




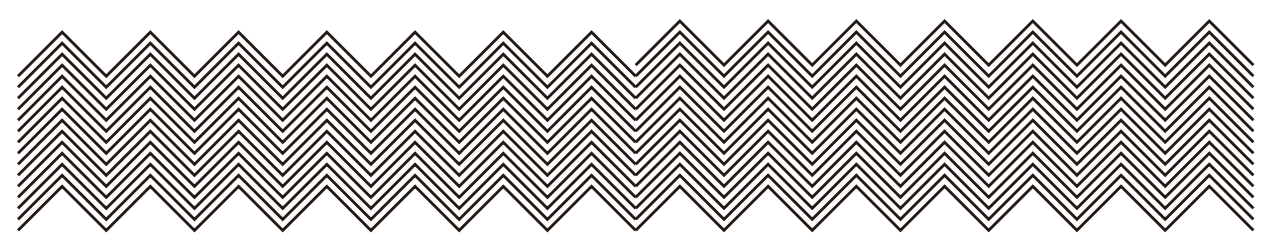

A

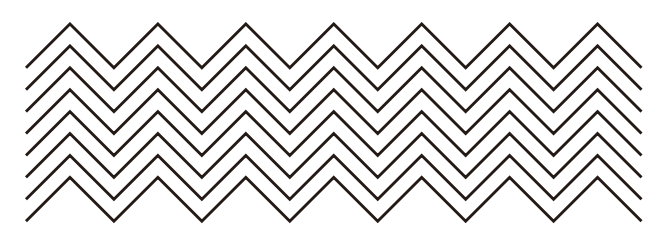

B

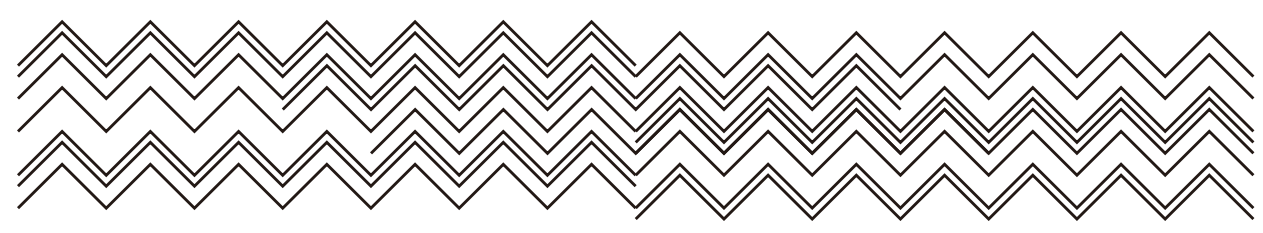

C

Gambar 5. llustrasi hipotetik susunan molekul lilin parafin; a) lilin parafin padat dengan rantai atom karbon lebih banyak dan jarak antara molekul yang lebih dekat; b) lilin parafin cair dengan rantai atom karbon lebih pendek dan jarak antar molekul lebih jauh; dan c) susunan molekul lilin parafin campuran dan jarak antar molekul yang berselang.

Dari ilustrasi Gambar 5 dapat dilihat bahwa lilin parafin padat memiliki susunan molekul lebih rapat karena gaya interaksi antar-molekulnya lebih kuat sedangkan lilin parafin cair susunannya lebih renggang dengan gaya antar molekul lebih lemah. Lilin parafin campuran memiliki struktur akhir molekulnya selang-seling antara rapat dan renggang. Fenomena tersebut menjelaskan mengapa pencampuran dua jenis lilin parafin menghasilkan suatu entitas baru dengan sifat termal yang berbeda.

Dari Gambar 4 terlihat bahwa kurva hasil pengukuran DSC untuk semua variasi campuran lilin parafin menunjukkan adanya 2 puncak. Hal tersebut menunjukkan bahwa mencampurkan kedua jenis lilin parafin tidak menghasilkan suatu senyawa baru, tetapi hanya menghasilkan suatu entitas baru yang komponenkomponen penyusun di dalamnya tetap 
ada dan terbaca dalam kurva DSC. Dengan kata lain, pencampuran lilin parafin padat dan cair tidak disertai reaksi kimia yang menghasilkan senyawa baru tetapi hanya menghasilkan campuran yang homogen dan berinteriaksi secara fisika dan mempengaruhi ikatan antarmolekulnya, sehingga menghasilkan sifat termal yang berbeda dari sifat termal masingmasing lilin parafin penyusunnya.

\section{KESIMPULAN}

Pencampuran lilin parafin padat dan cair dapat menghasilkan entitas baru dengan sifat termal yang berbeda. Titik leleh masing-masing campuran dengan rasio $9: 1 ; 8: 2 ; 7: 3$; dan $6: 4$ adalah 60,4 ; 57,$8 ; 57,1$ dan 51,4 으. Trend penurunan titik leleh tersebut mengindikasikan kecenderungan untuk turun lebih rendah lagi dengan melanjutkan seri komposisi pencampuran, sehingga PCM campuran yang disintesa dapat digunakan sebagai material inti pada pembuatan MPCM untuk digunakan sebagai thermal energy storage.

\section{UCAPAN TERIMA KASIH}

1. Politeknik STTT atas kesempatan meneruskan jenjang pendidikan magister dan beasiswa pendidikan yang diberikan.

2. Laboratorium Lingkungan Balai Besar Tekstil Bandung atas penyediaan fasilitas dan bahan penelitian.

\section{DAFTAR PUSTAKA}

1. Alkan, C., Sari, A., \& Karaipekli, A. (2011). Preparation, thermal properties and thermal reliability of microencapsulated $n$-eicosane as novel phase change material for thermal energy storage. Energy Conversion and Management, 52(1), 687-692. https://doi.org/10.1016/j.enconman.2010.07.047

2. Chang, R. (2010). CHE MISTRY (10th ed.). Mc Graw Hill Higher Education.

3. Chen, F., \& Wolcott, M. P. (2014). Miscibility studies of paraffin / polyethylene blends as form -stable phase change materials. EUROPEAN 
POLYMER J OURNAL, 52, 44-52.

https://doi.org/10.1016/j.eurpolymj.2013.09.027

4. Hale, B. D. V, Hoover, M. M. J ., Lockheed, N., Hunts ville, B. D., September, E., Cha, P., ... Space, N. M. (1971). Nasa Contractor Report Nasa Cr-51363.

5. Hopp, B., S mausz, T., Tombácz, E., Wittmann, T., \& Ignácz, F. (2000). Solid state and liquid ablation of polyethylene-glycol 1000: Temperature dependence. Optics Communications, 181(4), 337-343. https://doi.org/10.1016/S0030-4018(00)00777-X

6. Krupa, I., \& Mikova, G. (2007). POLYME R Phase change materials based on low-density polyethylene / paraffin wax blends. 43, 4695- 4705. https://doi.org/10.1016/j.eurpolymj.2007.08.022

7. Luyt, A. S., \& Krupa, I. (2008). Thermal behaviour of low and high molecular weight paraffin waxes used for designing phase change materials. 467, 117- 120. https://doi.org/10.1016/j.tca.2007.11.001

8. Mondal, S. (2008a). Phase change materials for smart textiles - An overview. Applied Thermal Engineering, 28(11-12), 1536- 1550. https://doi.org/10.1016/j.applthermaleng.2007.08.009

9. Mondal, S. (2008b). Phase change materials for smart textiles - An overview. Applied Thermal Engineering, 28(11-12), 1536- 1550. https://doi.org/10.1016/] .APPLTHER MALENG .2007.08.009

10.S. Himran, A. S. (1994). Characterization of Alkanes and Paraffin Waxes for Application as Phase Change. Energy Sources J ournal Volume, 16(1), 117128.

11. Sarier, N., \& Onder, E. (2012). Organic phase change materials and their textile applications: An overview. Thermochimica Acta, 540, 7-60. https://doi.org/10.1016/J .TCA.2012.04.013

12.Sharma, S. D. (2005). LATENT HEAT STORAGE MATERIALS AND SYSTEMS : A REVIEW. 1-56. https://doi.org/10.1081/G E-200051299 